\title{
The Second Young Environmental Scientist (YES) meeting 2011 at RWTH Aachen University - environmental challenges in a changing world
}

\author{
Markus Brinkmann ${ }^{1 *}$, Dominic Kaiser ${ }^{2}$, Sabrina Peddinghaus ${ }^{1}$, Matthias Leonhard Berens ${ }^{1}$, Jennifer Bräunig ${ }^{1}$, \\ Nika Galic ${ }^{3}$, Mirco Bundschuhn ${ }^{4}$, Jochen P Zubrod ${ }^{4}$, André Dabrunz ${ }^{4}$, Tao Liư ${ }^{5}$ Michael Melato ${ }^{6}$, Claudia Mieiro ${ }^{7}$, \\ Stephanie Sdepanian ${ }^{8}$, Ola Westman ${ }^{9}$, Stefan Kimmel $^{10}$ and Thomas-Benjamin Seiler ${ }^{1}$
}

\begin{abstract}
This article reports on the second Young Environmental Scientists Meeting that was hosted from 28 February to 2 March 2011 by the Institute for Environmental Research at RWTH Aachen University, Germany. This extraordinary meeting was again initiated and organized by the Student Advisory Council under the umbrella of Society of Environmental Toxicology and Chemistry Europe. A movie about the meeting and the abstracts of poster and platform presentations are freely available as supplemental material of this article.
\end{abstract}

The second Young Environmental Scientists Meeting (YES Meeting) was hosted from 28 February to 2 March 2011 by the Institute for Environmental Research at RWTH Aachen University, Germany http://www.bio5. rwth-aachen.de. This extraordinary meeting was again initiated and organized by the Student Advisory Council (SAC) in liaison with the local organization committee and the scientific committee under the umbrella of Society of Environmental Toxicology and Chemistry (SETAC) Europe. The chair persons of these committees, namely Markus Brinkmann, Sabrina Peddinghaus (both RWTH Aachen University, Germany), and Dominic Kaiser (Goethe University Frankfurt, Germany) ensured a scientifically ambitious and fruitful meeting in a pleasant ambience under the motto "Environmental challenges in a changing world".

Just like 2009 in Landau, Germany, this student-only meeting was again exclusively organized by students and with the well-known special benefits for students: no conference fees were charged and every participant received a travel grant. Due to the remarkable financial support by the "Fonds der Chemischen Industrie" (FCI) of the German Chemical Association (VCI), the Rector

\footnotetext{
* Correspondence: markus.brinkmann@bio5.rwth-aachen.de 'Department of Ecosystem Analysis, Institute for Environmental Research, RTWH Aachen University, Worringerweg 1, 52074 Aachen, Germany Full list of author information is available at the end of the article
}

of RWTH Aachen University, The Interdisciplinary Forums of RWTH Aachen University, ProRWTH, SETAC Europe, the SETAC Europe German Language Branch, Wimek/SENSE, Environmental Sciences Europe, and a number of companies (BASF, Bayer CropScience, Dr. Knoell Consult, Harlan Laboratories Ltd., Hydrotox, Syngenta), it was possible to announce full reimbursements of travel expenses for all participants invited to present their work during the YES meeting.

The scientific committee peer reviewed more than 130 abstracts in the field of nanoparticles, omics and biomarkers, aquatic and terrestrial ecotoxicology, modeling, environmental chemistry, management, and remediation techniques and finally invited 90 presenters from all over the world. Due to the selection process, not the financial situation but the quality of the submitted abstracts was the main aspect for invitation. Thus, the overall quality of presentations was very good, meeting the SETAC motto: "quality through science". Environmental issues at the cutting edge of science were presented in 44 platform and 46 poster presentations. An extended time for discussion of $15 \mathrm{~min}$ after each platform presentation gave room for in-depth discussions on one of the seven sessions covering the broad spectrum of science represented by SETAC. Besides the idea of the financial support, the student-only atmosphere is 


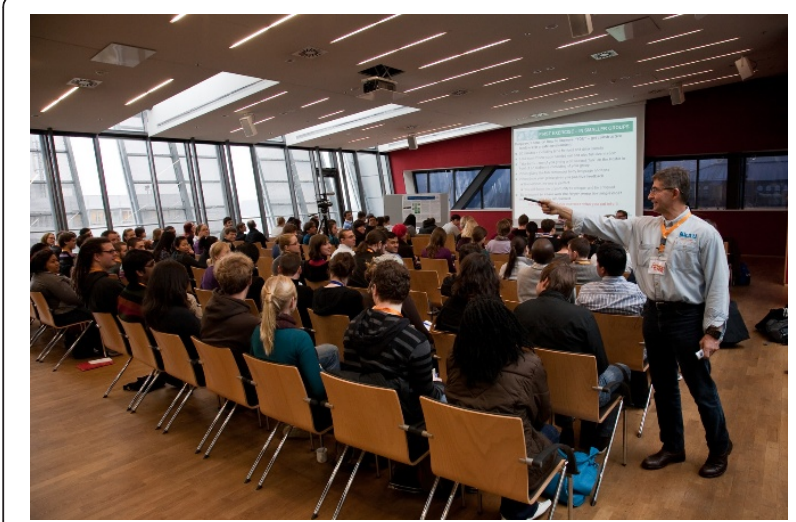

Figure 1 Peter Chapman during his workshop "Written and spoken science - Guidance to excellent publications and presentations". (Photograph: Sebastian Hudjetz). one of the key aspects of the meeting, which leads to unstressed and fruitful discussions.

During his amazing workshop "Written and spoken science - Guidance to excellent publications and presentations", Dr. Peter Chapman (Golder Associates, Vancouver, Canada) highlighted vital aspects of writing papers and preparing posters or platform presentations (Figure 1). In interactive group working slots, the students discussed and practiced presentation techniques and their critical view on scientific publications. The extraordinarily positive feedback from students demonstrates not only the demand for such lessons but also the enormous engagement Peter showed during his workshop (Figure 1).

Career talks - a regular SAC activity - given by Prof. Dr. Juliane Hollender (EAWAG, Switzerland) and Dr.

Table 1 Platform presentations given in one of the seven sessions during the second YES Meeting (Aachen, Germany) Session 1 "Nanoparticles: fate, effects and risks" (Chairs: Dominic Kaiser, André Dabrunz)

Pang et al., Roskilde University, Denmark

Dabrunz et al., University of Koblenz-Landau, Germany

Seitz et al., University of Koblenz-Landau, Germany

Völker et al., University Frankfurt, Germany

Gil-Allué et al., Eawag, Switzerland

Thit et al., Roskilde University, Denmark
Assessing risks of manufactured nanomaterials - are current EU regulations sufficient?

Toxicity of two stable $\mathrm{TiO} 2$ nanoparticle suspensions to Daphnia magna in acute and chronic test systems

Titanium dioxide nanoparticles reduce pirimicarb toxicity to Daphnia magna at ambient UV irradiation

Chronic effects of nanosilver to Daphnia magna

Uptake and toxicity of engineered silver nanoparticles to a cell wall free mutant of Chlamydomonas Reinhardtii

Effects of nano-sized CuO and ionic Cu: toxicity to Daphnia magna and tight epithelial cells

Session 2 "Omics and biomarkers: Linking suborganismic responses to ecologically relevant effects." (Chairs: Markus Brinkmann, ThomasBenjamin Seiler)

Panchout et al., University of Le Havre, France
Delov et al., Fraunhofer Institute of Molecular
Biology and Applied Ecology IME, Germany
Velki et al., Josip Juraj Strossmayer University Osijek,
Croatia
Nemec et al., LOEWE Biodiversity and Climate
Research Centre, Germany), Germany
Kanerva et al., University of Turku, Finland

Comparison of extraction protocols of gills proteins in the shore crab Carcinus maenas (I.) For 2DE application

The use of a transgenic fish line to refine the fish embryo test (FET) for vasotoxic effects

Suborganismic effects of formalin and temephos to earthworm Eisenia andrei

Genetic adaptation potential of Chironomus populations to temperature stress

High contaminant level do not affect the redox status of ringed seals - a comparison between two populations

Session 3 "Aquatic ecotoxicology: fate and effects of pollutants in the aquatic environment." (Chairs: Mirco Bundschuh, Jochen P. Zubrod)

Kunkel et al., University of Bayreuth, Germany

Simon et al., RWTH Aachen University, Germany

Zubrod et al., University of Koblenz-Landau, Germany

Nugroho et al., University of Bayreuth, Germany

Messing et al., University of Manitoba, Canada

Buresova et al., Alterra Wageningen, Netherlands Zafar et al., Wageningen University, Netherlands
Attenuation and dynamics of pharmaceuticals in a German stream

Chemo- and bioanalyses of the partitioning of radiolabelled organic chemicals in sediment-water-organism-systems

Effects of the fungicide Tebuconazole on an aquatic decomposer-detritivore system

Effects of copper on freshwater mussels: distribution, bioaccumulation, and effects on calcium homeostasis

The impact of eight herbicides at environmentally relevant concentrations in Prairie Pothole wetlands on aquatic invertebrates

Effects of pesticides on aquatic and terrestrial plants

Ecological impacts of time-variable exposure regimes to the fungicide azoxystrobine on freshwater communities in outdoor microcosms 
Table 1 Platform presentations given in one of the seven sessions during the second YES Meeting (Aachen, Germany) (Continued)
Englert et al., University of Koblenz-Landau,
Germany
The neonicotinoid thiacloprid affects the interaction of Gammarus fossarum and Baetis spp.
Agatz et al., University of York, United Kingdom
Effects of imidacloprid and carbaryl on the individual feeding activity of Gammarus pulex (L.)
Wollenweber et al., RWTH Aachen University, Germany
Assessing the endocrine disrupting potential of Bacillus thuringiensis israelensis based
Seeland et al., LOEWE Biodiversity and Climate insecticides
Research Centre, Germany
Uncertainties in aquatic ecotoxicological risk assessment

\section{Session 4 "Terrestrial ecotoxicology: Biodiversity and terrestrial ecosystem functions." (Chairs: Stefan Kimmel, Bernd Guckenmus)}

\author{
Abongwa et al., University of Buea, Cameroon \\ Mikowska et al., Jagiellonian University, Poland \\ Šrut et al., University of Zagreb, Croatia \\ Motejlová et al., Institute of Chemical Technology \\ Prague, Czech Republic \\ Selonen et al., University of Helsinki, Finland \\ Peric et al., University of Barcelona, Spain
}

Evaluation of the efficacy of crude aqueous extract of Senna occidentalis in the amelioration of tetracycline-induced hepatotoxicity and nephrotoxicity in rabbits Genetic diversity in the small rodent Myodes glareolus from isolated populations and populations from heavy metal polluted areas

Genotoxicity assessment of soils near heavy traffic roads using native populations of earthworm Aporrectodea caliginosa

The effect of 1,4-dichlorobenzene on soil organisms

Effects of lead on pine forest ecosystem in a shooting range area

Comparative study of aquatic and terrestrial toxicity of some aprotic and protic ionic liquids

Session 5 "From the screen to field: Modeling effects and exposure." (Chairs: Nika Galic, André Gergs)
Tessema et al., Friedrich Schiller University of Jena Germany
Factors controlling the hydrochemistry of the groundwater aquifer of Jena Biodiversity
experimental field
Hernout et al., University of York, UK
Predicting exposure of bats to soil-associated heavy metals
Hamda et al., Jagiellonian University, Poland
Decomposition analysis of LTREs may help to design short-term ecotoxicological tests: Population Modeling Approach
Meli et al., Roskilde University, Denmark
Springtail avoidance behavior in heterogeneously contaminated environments: an individual-based model
Labite et al., University College Dublin, Ireland
A review and evaluation of plant protection product ranking tools used in agriculture

Session 6 "Environmental chemistry: Detecting emerging contaminants in a changing environment." (Chairs: Tao Liu, Thorsten Junge)

\footnotetext{
Sousa et al., University of Porto, Portugal

Meierjohann et al., Åbo University, Finland

Luft et al., Federal Institute of Hydrology (BfG), Germany

Ali et al., University of Antwerp, Belgium

Fierens et al., VITO, Belgium

Messing et al., University of Manitoba, Canada
}

Solar-induced transformation of Lorazepam (Lorenin ${ }^{\circledR} 1 \mathrm{mg}$, Wyeth) in distilled water using a pilot plant with CPCs: direct photolysis vs. TiO2-assisted photocatalysis Seasonal Variations of Pharmaceuticals in a River/Lake System in Eastern Finland Biodegradation of biocides in sewage sludge

An exposure assessment of novel brominated flame retardants to toddlers and adults using dust samples from Belgian homes and offices and UK day care centers and schools Phthalates in cow milk: possible contamination pathways at farm level

Air concentrations and bulk atmospheric deposits of pesticides in relation to wetland water quality

Session 7 "Implementing scientific knowledge in decision making: Management and remediation techniques." (Chairs: Michael Melato, Kerstin Bluhm)

Bluhm et al., RWTH Aachen University, Germany

Mansfield et al., University of Manchester, UK

Sizmur et al., University of Reading, UK

Thüns et al., University of Bayreuth, Germany

Heger et al., RWTH Aachen University, Germany
Ecotoxicological Investigations of potential biofuels

The restoration of Manchester Docks to Salford Quays: 30 years of habitat management Innoculation of earthworms during contaminated land relamation and restoration: impacts on metal mobility and availability

Comparison of the characteristic travel distance of PAHs calculated by the OECD model "The tool" and measured values using peat bogs as passive samplers

What's up inside the reactor - Biotests for risk assessment of biofuel fermentation 
Steve Maund (Syngenta, Switzerland) provided important and very personal insights into career planning and what it is like to work at a federal research institute or in industry, respectively. Both senior scientists assured that a well-developed scientific network is crucial for career progress, and therefore highlighted the importance of such meetings, where students from all over the world come together.

The Job Corner allowed representatives from some of the meeting sponsors, namely BASF, Dr. Knoell Consult, and Harlan Laboratories Ltd. to introduce their companies to the participants, who had the chance to get in contact with potential future employers. The participating companies attracted a lot of students asking for jobs as well as internships

"Environmental challenges in a changing world" were identified through the presentations of the participants and then were discussed. So the main theme of the meeting was carried out.

A feedback questionnaire about the meeting reflected the expectations of the organizers well: Most of the participants considered this meeting very valuable and a good chance for first timers to get familiar with scientific meetings. According to the participants, what was preferable in particular was the scientific spirit during the congress which was not clouded by strategic considerations but driven by the curiosity for the research of their fellow students.

Apparently, the 2nd YES meeting turned out to be again a great success and thus will be kept as a fixed event within the SAC.

For further information, press reviews, as well as updates on the next YES Meeting, please check our meeting website http://yes2011.sac-online.eu

In order to promote the activities of the SAC and to present the results of YES to a broader audience, a video clip of the meeting has been prepared by Matthias Leonhard Berens. The video (Link), as well as abstracts of poster and platform presentations (Link) are freely accessible as supplemental material (see additional files 1 and 2) of this article. The presenters and titles of platform presentations given during the meeting are given in Table 1.

\section{Additional material}

Additional file 1: The $2^{\text {nd }}$ Young Environmental Scientists meeting March 2011, Aachen, Germany - Abstracts.

Additional file 2: The $2^{\text {nd }}$ Young Environmental Scientists meeting March 2011, Aachen, Germany - video link.

\section{Acknowledgements}

The Student Advisory Council wants to thank all sponsors, supporters, the local organizers, all participants, Juliane and Steve, and especially Peter for their considerable support and for the great time we all had during the meeting. We also want to acknowledge Kevin MacLeod (http://incompetech. com) for providing royalty-free music for the meeting movie which is licensed under Creative Commons Attribution 3.0 (http://creativecommons. org/licenses/by/3.0/)

This meeting report is an extended version of the SETAC Globe article published in the 2011 April issue by the Student Advisory Council of SETAC Europe.

\section{Author details}

'Department of Ecosystem Analysis, Institute for Environmental Research, RTWH Aachen University, Worringerweg 1, 52074 Aachen, Germany ${ }^{2}$ Department Aquatic Ecotoxicology, Institute for Ecology, Evolution and Diversity, Goethe University Frankfurt, Siesmayerstr. 70, 60054 Frankfurt/Main, Germany ${ }^{3}$ Wageningen Institute for Environment and Climate Research, Droevendaalsesteeg 3a, Lumen (Building 100), Wageningen, Netherlands ${ }^{4}$ Institute for Environmental Sciences, University of Koblenz-Landau, Forststr. 7, 76829 Landau, Germany ${ }^{5}$ Linnaeus University, School of Natural Sciences, 39182 Kalmar, Sweden ${ }^{6}$ Faculty of Applied Science, Cape Peninsula University of Technology, P.O. Box 652, Cape Town 8000, South Africa ${ }^{7}$ CESAM and Department of Chemistry, University of Aveiro, Campus de Santiago, 3810-193 Aveiro, Portugal ${ }^{8}$ Lancaster University, Bailrigg, Lancaster Environment Centre, Lancaster, LA1 4YQ, UK ${ }^{9}$ School of Science and Technology, Örebro University, Man-Technology-Environment Research Centre, 70181 Örebro, Sweden ${ }^{10}$ Harlan Laboratories Ltd., Zelgliweg 1, 4452 Itingen, Switzerland

\section{Authors' contributions}

All authors were involved in the organization and/or conduction of the meeting and have read and approved the final manuscript.

\section{Competing interests}

The authors declare that they have no competing interests.

Received: 24 June 2011 Accepted: 5 September 2011

Published: 5 September 2011

doi:10.1186/2190-4715-23-29

Cite this article as: Brinkmann et al:: The Second Young Environmental Scientist (YES) meeting 2011 at RWTH Aachen University -

environmental challenges in a changing world. Environmental Sciences Europe 2011 23:29

\section{Submit your manuscript to a SpringerOpen ${ }^{\circ}$ journal and benefit from:}

- Convenient online submission

- Rigorous peer review

- Immediate publication on acceptance

- Open access: articles freely available online

- High visibility within the field

- Retaining the copyright to your article

Submit your next manuscript at $\boldsymbol{s p r i n g e r o p e n . c o m ~}$ 